\title{
Major differences in the levels of redox status and antioxidant defence markers in the erythrocytes of pre- and full-term neonates with intrauterine growth restriction
}

\author{
Ágnes Ferencz ${ }^{\mathrm{a}}$, Hajnalka Orvos ${ }^{\mathrm{b}}$, Edit Hermesz ${ }^{\mathrm{a}, *}$ \\ a Department of Biochemistry and Molecular Biology, Faculty of Science and Informatics, P.O. Box 533, H-6701 Szeged, Hungary \\ ${ }^{\mathrm{b}}$ Department of Obstetrics and Gynaecology, University of Szeged, P.O. Box 533, H-6701 Szeged, Hungary
}

\section{A R T I C L E I N F O}

\section{Article history:}

Received 30 September 2014

Received in revised form 16 February 2015

Accepted 17 February 2015

Available online 24 February 2015

\section{Keywords:}

Antioxidant defence

IUGR

Oxidative stress

Peroxynitrite

Umbilical cord blood

\begin{abstract}
A B S T R A C T
Intrauterine growth restriction (IUGR) is a pleiotropic complication of pregnancy. Prematurity and growth abnormalities are common risk factors for perinatal morbidity and mortality. Free radical damage has been recognized as a common pathogenic mechanism of many neonatal diseases. The aim of the present study was to characterize the possible links between the level of maturity, the birthweight and the antioxidant status of neonates born with IUGR. Our data suggest that the stress markers measured on the cord blood of neonates with IUGR and mature, healthy neonates do not necessarily reflect the extent of oxidative stress. However, significant correlations were found between the maturity of the neonates with IUGR and the oxidative damage. The mature IUGRs exhibited $\mathrm{ONOO}^{-}$accumulation and increased lipid peroxidation more frequently as compared with the pre-term group. The results suggest that the oxidative injury in IUGR may depend on the level of maturity and the birthweight.
\end{abstract}

(c) 2015 Elsevier Inc. All rights reserved.

\section{Introduction}

Pregnancy is a physiological state associated with an enhanced metabolism and an increased demand for oxygen. Premature infants are at particular risk from oxidative stress, as neither the endogenous nor the passively acquired exogenous antioxidant defence system accelerates in maturation until late in the third trimester [1,2]. Intrauterine growth restriction (IUGR) is one of the major complications of pregnancy and accounts for significant neonatal mortality and morbidity [3]. The development of IUGR may be a consequence of various factors, including an abnormal fetomaternal blood circulation, genetic disorders, pregnancy-induced hypertension, pregestational diabetes, a lean umbilical cord, previous intrauterine infections, a poor nutritional state of the mother, frequent cigarette smoking [4] and toxin or drug exposure [5]. However, in the vast majority of the cases the cause remains idiopathic.

IUGR is often complicated by intrauterine hypoxia and may induce the generation of reactive oxygen species (ROS) and foetal oxidative stress, resulting in serious consequences for the foetus, such as low birthweight and prematurity [6]. Neonates with IUGR

\footnotetext{
* Corresponding author. Tel.: +36 62 544887; fax: +36 62544887.

E-mail address: hermesz@bio.u-szeged.hu (E. Hermesz).
}

are more susceptible to ROS-induced oxidative damage because their enzymatic and non-enzymatic antioxidant defence systems and the ability to undergo induction during a hyperoxic challenge are impaired [7].

To eliminate the harmful effects of ROS, cells are equipped with an efficient antioxidant defence system, including enzymes such as superoxide dismutase (SOD), catalase (CAT), hemeoxygenases (HOs), and low-molecular weight antioxidants such as glutathione (GSH) and metallothioneins (MTs) [8,9]. SOD catalyses the reduction of the superoxide anion $\left(\mathrm{O}_{2}{ }^{-}\right)$to hydrogen peroxide $\left(\mathrm{H}_{2} \mathrm{O}_{2}\right)$. In a subsequent step, CAT stimulates the degradation of $\mathrm{H}_{2} \mathrm{O}_{2}$ to molecular oxygen and water [10]. The MTs are small proteins with unusually high cysteine content. This confers their high metal-binding and ROS-reducing properties [11]. The HOs play roles in heme degradation, yielding equimolar quantities of biliverdin, carbon monoxide (CO) with important free radicalscavenging properties and free Fe ions. In mature neonates, a considerable proportion of the plasma total antioxidant capacity originates from bilirubin [12]. HO-2 is a constitutive, and HO-1 an inducible isoform of $\mathrm{HO}$, an antioxidative, anti-inflammatory and cytoprotective enzyme that is induced in response to cellular stress, including oxidative stress [13].

Nitric oxide (NO) may be an important factor for the regulation of blood pressure and oxygen delivery to the foetus [14]. Umbilical cord blood vessels lack innervations, and endothelial cells must 
Table 1

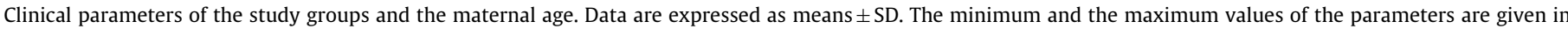
parentheses.

\begin{tabular}{|c|c|c|c|}
\hline & Full-term neonates with normal weight & Full-term neonates with IUGR & Pre-mature neonates with IUGR \\
\hline Gestational age at delivery (weeks) & $39.2 \pm 0.77(38-40+2)$ & $38.741 .31(37-40+4)$ & $34.01 \pm 1.62(30-36)$ \\
\hline Birth weight $(\mathrm{g})$ & $3409 \pm 455(3190-4340)$ & $2354238.8(2090-2490)$ & $1518 \pm 460.5(980-2120)$ \\
\hline The $\mathrm{pH}$ of blood samples & $7.25 \pm 0.11(7.04-7.42)$ & $7.240 .088(7.1-7.36)$ & $7.20 \pm 0.142(7.05-7.3)$ \\
\hline $1 \mathrm{~min}$ APGAR & $8.83 \pm 1.37(6-10)$ & $8.361 .65(6-10)$ & $7 \pm 1.63(4-9)$ \\
\hline Maternal age (years) & $29.9 \pm 5.74(22-42)$ & $28.96 .55(20-41)$ & $29.3 \pm 7.22(21-42)$ \\
\hline
\end{tabular}

therefore play a major role in the local control of blood flow [15]. NO derived from endothelial nitric oxide synthase (eNOS) is considered the main vasodilator agent in fetoplacental vessels [16]. The simultaneous generation of $\mathrm{NO}$ and $\mathrm{O}_{2}{ }^{\circ}-$ in sufficiently high concentrations in the same compartment favours the production of a toxic reaction product, peroxynitrite anion $\left(\mathrm{ONOO}^{-}\right)$. $\mathrm{ONOO}^{-}$and other reactive nitrogen species can affect the cell functions through the oxidation or nitration of various cellular targets [17].

Under stress conditions, genes coding for molecules involved in biological defence and cellular repair are markedly upregulated, and the changes in gene expression can be characteristic, sensitive and measurable endpoints [18]. Members of this antioxidant defence system are useful biomarkers of the oxidant-antioxidant status of neonates with IUGR. The aim of the present study was to characterize the possible links between the level of maturity, the birthweight and the antioxidant status of neonates born with IUGR. We report data on macromolecular damage, the accumulation of powerful oxidants such $\mathrm{ONOO}^{-}, \mathrm{H}_{2} \mathrm{O}_{2}$, the activities of the antioxidant enzymes SOD and CAT, and the expressions of a set of genes coding for members of antioxidant defence system ( $\operatorname{sod} 1$, sod2, cat, $m t-1, m t-2$, ho-1, ho-2 and enos) from the aspects of the level of maturity and the birthweight of neonates with IUGR.

\section{Materials and methods}

\subsection{Human subjects}

The blood samples were obtained from the Department of Obstetrics and Gynaecology at the University of Szeged, Hungary. The Ethics Committee of the Department of Obstetrics and Gynaecology approved the study protocol (149/2012). 24 mature neonates with normal weight and 28 mature and 28 premature neonates with IUGR of either sex were examined. The neonates were considered premature if they were born before the gestational age of 37 weeks and full-term if the delivery occurred after 37 weeks. Newborns that had a history of difficult delivery and foetal distress, or showed malformations or evidence of genetic disorders were excluded. The nutritional status of the mothers during pregnancy was satisfactory; no case of malnutrition occurred. Smoking mothers and their neonates were also excluded from this study.

Blood was taken from the umbilical artery, before the birth of the placenta. Blood coagulation was inhibited by EDTA. The blood samples were centrifuged at $3000 \mathrm{rpm}$ for $20 \mathrm{~min}$ at $4{ }^{\circ} \mathrm{C}$, and the plasma and the buffy coat were removed. The red blood cell (RBC) phase was washed twice with 2 volumes of isotonic saline solution at $\mathrm{pH} 7.0$. The samples were stored at $-80^{\circ} \mathrm{C}$ until processing (Table 1).

\subsection{RNA extraction, reverse transcription and PCR amplification}

Approximately, $100 \mathrm{mg}$ of frozen RBC were homogenized in RNA Bee reagent (Tel-Test, Inc.) and total RNAs were prepared according to the procedure suggested by the manufacturer. Total RNA was routinely treated with $100 \mathrm{U}$ RNAse-free DNAseI (Thermo Scientific) to avoid any DNA contamination.
For the quantification of $m t-1$ and $m t-2$, sod1 and sod2, cat, enos, ho-1 and ho-2 mRNAs, reverse transcription followed PCR amplifications (RT-PCRs) were performed. First-strand cDNAs were synthesized by using $5 \mu \mathrm{g}$ total RNAs as templates, $200 \mathrm{pmol}$ of each dNTP (Thermo Scientific), $200 \mathrm{U}$ Maxima H Minus Reverse Transcriptase (Thermo Scientific) and 500 pmol random hexamer primers (Sigma) in a final volume of $20 \mu \mathrm{L}$, and incubated for $10 \mathrm{~min}$ at $37^{\circ} \mathrm{C}$, followed by $1 \mathrm{~h}$ at $52^{\circ} \mathrm{C}$. One microliter reverse transcription product was added to $25 \mu \mathrm{L}$ DreamTaq Green PCR Master Mix 2x (Thermo Scientific). Amplification was performed in a PTC 200 Peltier Thermal Cycler (MJ Research) using 15 cycles of $95^{\circ} \mathrm{C}$ for $30 \mathrm{~s}, 55^{\circ} \mathrm{C}$ for $30 \mathrm{~s}$, and $72{ }^{\circ} \mathrm{C}$ for $30 \mathrm{~s}$ for the $18 \mathrm{~S}$ rRNA, used as internal reference and 30 cycles for $m t-1$ and $m t-2$, sod 1 and sod2, cat, enos, ho- 1 and ho- 2 mRNAs, respectively. The amplified products were detected on a $2 \%$ agarose gel. The relative levels of mRNAs are expressed as ratios (mRNA/18S rRNA).

\subsection{Primers}

The following primer sets were selected: sod1: F: aagatggtgtggccgatgtg and $\mathrm{R}$ : ctacagctagcaggataacag; sod2: $\mathrm{F}$ : caaggctcaggttggggttg and R: gctgggatcattagggtagtatg; cat: F: cacagaagatggtaactggg and R: ggcgatgtccatctggaatc; enos: F: cactgagcccgtggcagtag and R: ggcaggcagcgccaccgacg; $m t-1$ : F: atggaccccaactgctcctg and R: gttcccacatcaggcacagc; $m t-2: \mathrm{F}$ : atggaccccaactgctcctg and R: cggtcacggtcagggttgtac; ho-1: F: gctgctggtggcccacgctt and $\mathrm{R}$ : ctctggtccttggtgtcatgg; ho-2: $\mathrm{F}$ : tggcccacgcatacaccegc and R: ggtctctctggccagtgtgga. For the normalization of sods, cat, enos, mts and hos mRNAs, the level of carp 18S rRNA was used as internal standard, detected with primer pairs F: gaaacggctaccacatccaagg, and R: ccgctcccaagatccaactacg.

\subsection{Densitometry}

Images of the ethidium bromide-stained agarose gels were digitized with a GDS 7500 Gel Documentation System and analyzed with the GelBase/GelBlot ${ }^{\mathrm{TM}}$ Pro Gel Analysis Software (UVP).

\subsection{Enzyme activity measurement}

The RBCs were hemolysed by the addition of distilled water at a ratio of 1:9. Except for SOD activity determinations, the aliquots of the hemolysates were used directly. The quantity of protein was determined with Folin reagent, using bovine serum albumin as standard [19]. Biomate 5 Double-Beam UV-vis photometer recording (Thermo Spectronic) was used for SOD measurements and GENESYS 10S UV-vis spectrophotometer (Thermo Scientific) was used for all the other parameters.

SOD (EC 1.15.1.1) activity was determined on the basis of the inhibition of the epinephrine-adrenochrome autoxidation [20]. Spectrophotometric measurement was carried out at $480 \mathrm{~nm}$. The results were expressed in $\mathrm{U} / \mathrm{mg}$ protein.

CAT (EC 1.11.1.6) activity was determined spectrophotometrically at $240 \mathrm{~nm}$ by the method of Beers and Sizer [21] and specific 


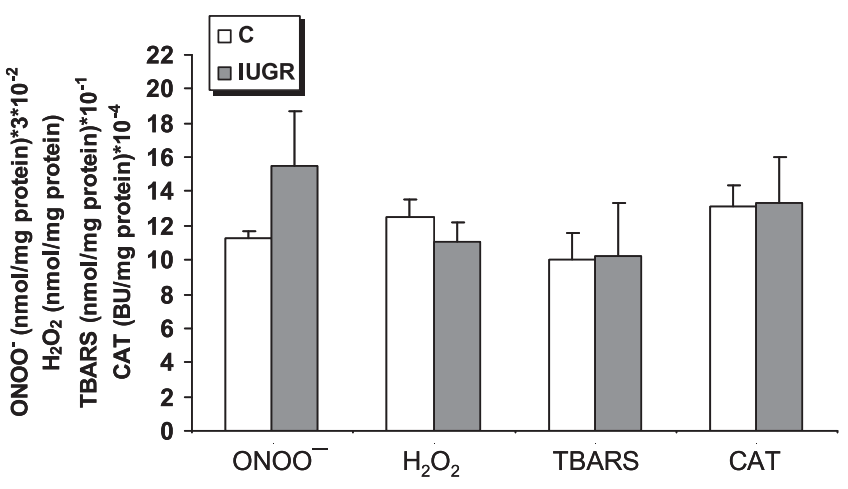

Fig. 1. The levels of $\mathrm{ONOO}^{-}, \mathrm{H}_{2} \mathrm{O}_{2}$, lipid peroxidation (TBARS), and the CAT activity in the cord red blood cells of mature, healthy neonates (C) and neonates with IUGR. Data were expressed as means \pm SEM from measurements on 24/56 samples.

CAT activity was expressed in Bergmeyer units (BU)/mg protein ( 1 $\mathrm{BU}=$ decomposition of $1 \mathrm{~g} \mathrm{H}_{2} \mathrm{O}_{2} /$ min at $25^{\circ} \mathrm{C}$ ).

\subsection{Lipid peroxidation estimation assay}

The level of thiobarbituric acid-reactive substances (TBARS) is regarded as an appropriate indicator of the extent of lipid peroxidation (LPO) [22]. LPO was estimated by a TBARS assay at $532 \mathrm{~nm}$ against a blank that contained the thiobarbituric acid (TBA) reagent $\left(0.15 \mathrm{~g} / \mathrm{mL} \mathrm{TCA}, 3.75 \times 10^{-3} \mathrm{~g} / \mathrm{mL}\right.$ TBA and $\left.0.25 \mathrm{M} \mathrm{HCl}\right)$ as described by Serbinova et al. [23].

\subsection{Determination of $\mathrm{H}_{2} \mathrm{O}_{2}$ production}

For the assay of $\mathrm{H}_{2} \mathrm{O}_{2}, 0.05 \mathrm{mg} / \mathrm{mL}$ horseradish peroxidase and $0.1 \mathrm{mg} / \mathrm{mL}$ o-dianisidine in sodium phosphate buffer $(100 \mathrm{mM}, \mathrm{pH}$ 6.5) was used. The $\mathrm{H}_{2} \mathrm{O}_{2}$ concentration was determined spectrophotometrically at $400 \mathrm{~nm}$ and was calculated as nmol/mg protein [24].

\subsection{Determination of $\mathrm{ONOO}^{-}$production}

$\mathrm{ONOO}^{-}$was assayed by diluting samples into $1.0 \mathrm{M} \mathrm{NaOH}(60: 1)$ and measuring the increase in absorbance at $302 \mathrm{~nm}$. As a control, samples were added to $100 \mathrm{mM}$ potassium phosphate ( $\mathrm{pH} 7.4$ ) $(60: 1)$. The decrease in absorbance was measured at neutral $\mathrm{pH}$ as $\mathrm{ONOO}^{-}$decomposes [25]

\subsection{Statistical analysis}

Statistical differences were calculated with one-way analysis of variance (ANOVA) (MedCalc Statistical Software version 9.4.2.0,

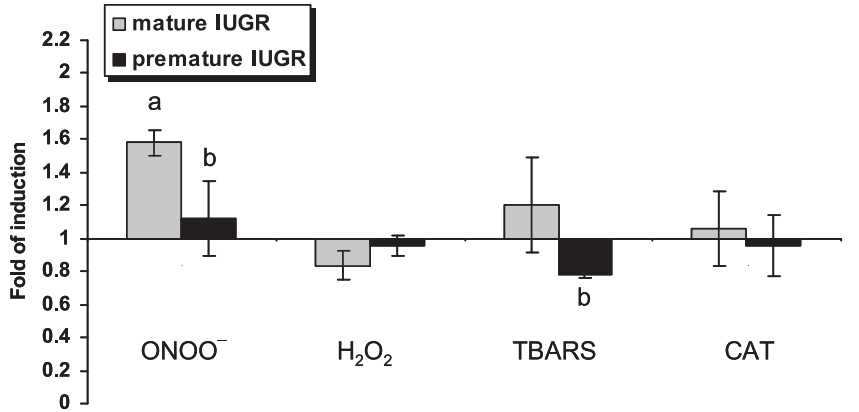

Fig. 3. Fold of change in the levels of $\mathrm{ONOO}^{-}, \mathrm{H}_{2} \mathrm{O}_{2}$, lipid peroxidation (TBARS), and the CAT activity in the cord red blood cells of mature and premature neonates with IUGR. For normalization the levels of mature, healthy neonates were used as reference. Significant difference was accepted at ${ }^{\mathrm{a} / \mathrm{b}} p \leq 0.05$. (a) A significant difference between the mature, healthy neonates and neonates with IUGR. (b) A significant difference between the mature and premature neonates with IUGR.

Broekstraat, Belgium) with a Student-Newman-Keuls follow-up test. Significant difference was accepted at ${ }^{\mathrm{a}, \mathrm{b}} p \leq 0.05$, ${ }^{\text {aa }} p \leq 0.01$ and aaa $p \leq 0.001$.

\section{Results}

\subsection{Comparative studies of mature, healthy neonates and} neonates with IUGR

The levels of oxidant molecules $\left(\mathrm{H}_{2} \mathrm{O}_{2}\right.$ and $\left.\mathrm{ONOO}^{-}\right)$and thiobarbituric acid-reactive substances (TBARS) and the activity of the $\mathrm{H}_{2} \mathrm{O}_{2}$-degrading CAT did not differ significantly between the IUGR and control groups (Fig. 1).

As concerns the mRNA levels of genes coding for antioxidant molecules, significantly lower amounts were measured for cat ( 20\%), ho-1 ( 40\%) and ho-2 $\sim 50 \%)$ in the IUGR group than in the controls. The $m t-2$ mRNA level was approximately 1.5 -fold higher in the neonates with IUGR than in the control group (Fig. 2). As a consequence of the relatively high individual fluctuations, the averages of the amounts of $m t-1$, sods and enos mRNA did not differ significantly (Fig. 2).

\subsection{Comparative studies of mature and premature neonates with IUGR}

There was no significant difference in the level of $\mathrm{H}_{2} \mathrm{O}_{2}$ or the activity of CAT between the mature and pre-term neonates with IUGR. However, the mature group exhibited a 1.5-fold higher accumulation of $\mathrm{ONOO}^{-}$, and also a higher TBARS level (Fig. 3). The levels of $\mathrm{ONOO}^{-}$and TBARS for the pre-term IUGR neonates were was more similar to those for the normal controls.

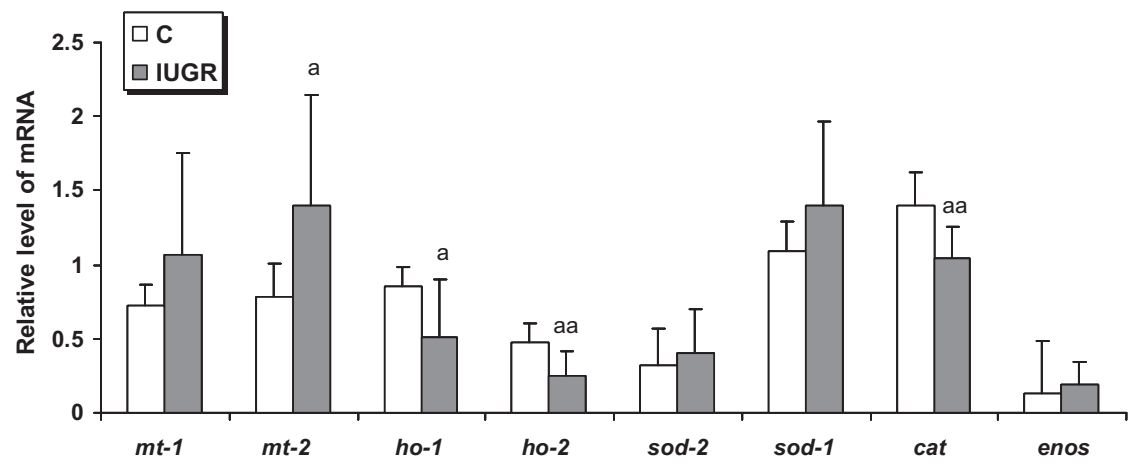

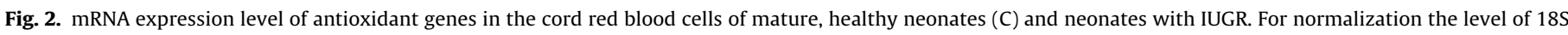
rRNA was used as an internal standard. Data were expressed as means \pm SEM from measurements on $24 / 28$ samples. ${ }^{\mathrm{a}} p<0.05$, ${ }^{\text {aa }} p<0.01 .1$. 


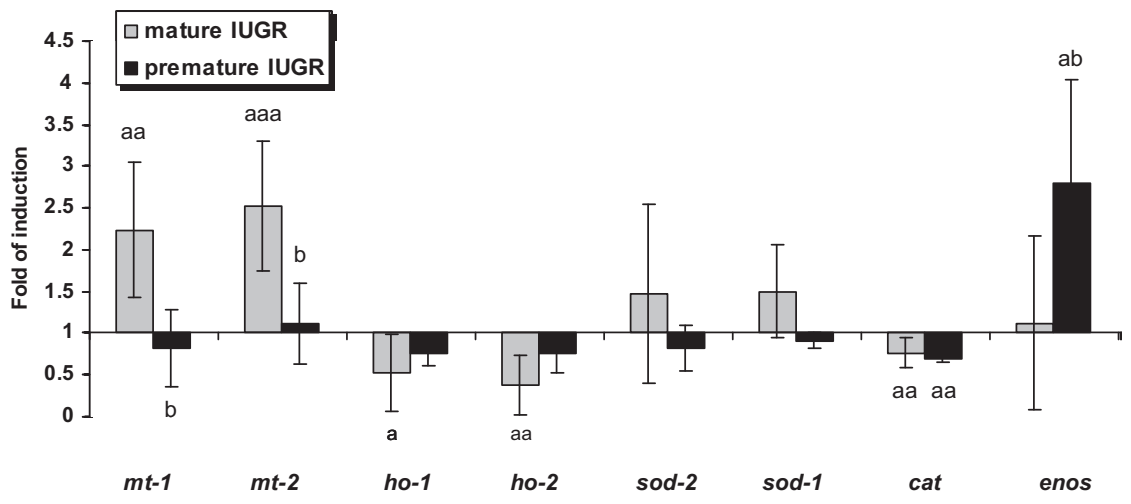

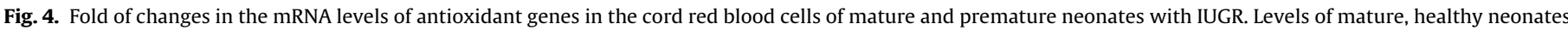

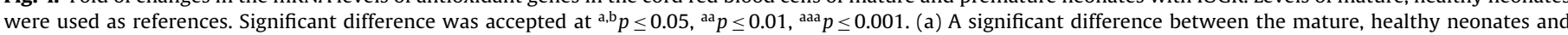
neonates with IUGR. (b) A significant difference between the mature and premature neonates with IUGR.

Marked differences were also observed between the mRNA levels of selected parameters in the groups of mature and premature IUGR neonates. There was a $\sim 60 \%$ difference in the level of the $m t-1$ and $m t-2$ mRNAs. The mRNA levels of both genes were approximately doubled in the mature IUGR neonates as compared with the pre-term IUGRs and also the normal controls (Fig. 4A). The transcription products of the ho genes were considerably lower in both IUGR groups; in the mature IUGRs, the levels of ho- 1 and ho- 2 mRNA were $\sim 50 \%$ and $40 \%$ of those for the control. In the premature IUGR group, both mRNA levels were lower by $25 \%$, though these changes were not significant. The level of cat mRNA was likewise lower in both IUGR groups: a significant $\sim 25 \%$ decreases were detected. The transcripts of the sod genes in the mature IUGR group were $\sim 1.5-$ fold those measured in the control and premature IUGR groups. In the premature IUGR group, the enos mRNA was $\sim 3$-fold that in the mature IUGR group (Fig. 4B). In this case, the mature neonates with or without IUGR exhibited similar mRNA levels.

\section{Discussion}

Since IUGR is postulated to be a pleiotropic complication of pregnancy, the identification of unit marker molecules or reaction pathways connected with this disorder poses a number of difficulties. Various studies have focused on the antioxidant status of IUGR or premature neonates, but only brief accounts have been given as concerns the comparison of premature and full-term neonates with IUGR from any aspect. The major finding of the present study is the importance of the age-based grouping of neonates with IUGR. Significant differences in the levels of specific stress markers relative to the control group were observed only when the full-term and pre-term IUGR neonates were grouped separately.

A higher degree of oxidative stress was detected in the cord blood of mature IUGR neonates as compared with the control and pre-term IUGR groups; the level of $\mathrm{ONOO}^{-}$was almost twice as high, indicating increased $\mathrm{O}_{2}{ }^{-}-$and $\mathrm{NO}$ production. The simultaneous generation of $\mathrm{NO}$ and $\mathrm{O}_{2}{ }^{-}-$in relatively high concentrations in the same compartment favours production of the toxic reaction product $\mathrm{ONOO}^{-}$[17]. Although $\mathrm{ONOO}^{-}$itself is not a free radical, it is a powerful oxidant, whose toxicity is manifested among others in LPO [17] and which plays a role in the pathophysiology of IUGR [26].

The elevated $\mathrm{ONOO}^{-}$and $\mathrm{O}_{2}{ }^{-}-$levels in the cord blood of mature neonates with IUGR were clearly reflected by an increased level of TBARS. NO, however, is a Janus-faced molecule. Since the umbilical cord blood vessels lack innervations, the NO production in the endothelial cells plays a major role in the local control of blood flow and in oxygen delivery to the foetus [15]. In this study, we have demonstrated a significantly higher level of the mRNA of eNOS in the cord blood samples of underdeveloped neonates with IUGR. In these cases, the increase in eNOS expression was not paralleled by $\mathrm{ONOO}^{-}$accumulation, suggesting an unaltered level of $\mathrm{O}_{2}{ }^{-}$. This is in accord with the fact that there were no significant differences in the expressions of the sod genes, and the activity of SOD was also unaltered (data not shown). Additionally, no significant changes were observed in the TBARS level in the cord blood of the premature neonates with IUGR. An insufficient level of vasodilatation of the umbilical vessels and reduced eNOS activity were earlier reported to be associated with neonates who were small for gestational age [16].

Evidence has recently been accumulating that $\mathrm{CO}$, best known for its toxicity, can function in a similar manner to NO [27] or may even interact with the NO-producing pathway [28]. CO is formed primarily as a product of heme degradation, which is catalysed by the HOs. The observation of substantial HO activity in the cord tissues supports the possibility of the accumulation of $\mathrm{CO}$ in sufficiently high amounts to play a role in fetoplacental blood flow regulation [29]. Our study presents evidence that the expressions of the ho genes are markedly low in IUGR neonates (regardless of the level of maturity) versus controls. Though the low expressions of both ho genes were characteristic for both IUGR groups, a significant difference was observed only for the full-term neonates with IUGR. Deficiencies in HO-1 have previously been found to be associated with pregnancy disorders, such as recurrent miscarriages, IUGR and pre-eclampsia [30]. Our results support this: the lower expression of ho in IUGR neonates might result in a decreased CO level and unsatisfactory fetoplacental blood flow. Moreover our data relating to the selected antioxidant molecules suggest that ho could serve as an indicative marker providing a possible link to the IUGR phenotype.

The presence of IUGR in full-term neonates was accompanied by significantly higher levels of expression of both $m t$ genes. MT, an important protein which binds bivalent metals, plays a significant role in numerous cellular metabolic processes, such as in maintaining $\mathrm{Zn}$ and $\mathrm{Cu}$ homeostasis and in $\mathrm{Cd}$ and $\mathrm{Hg}$ detoxification. Additionally, an increased MT level was demonstrated by Zapata et al. in the erythrocytes of pregnant women [31]. Elevated MT levels have been attributed to the proliferation and differentiation of blood cells in the process of erythropoiesis, the protective role of erythrocytes against the action of free radicals, and increased levels of estrogen and progesterone, hormones which induce the synthesis of MT [32]. A statistically significant increase in the level of MT protein has additionally been revealed in the plasma and RBCs of pregnant women and of their neonates with IUGR [4]. The possible physiological functions of MT in the placenta include 
temporary $\mathrm{Zn}$ storage and regulation of the $\mathrm{Zn}$ flow to the foetus, while restricting toxic metal transfer [33] and protection against the embryotoxic and teratogenic effects of a Zn deficiency [34], which may be caused by cigarette smoke, alcohol, gestational infection and exposure to environmental contaminants, including heavy metals and endocrine disrupters [35].

From an analysis of the parameters relating to the different IUGR groups, we can conclude that full-term neonates with IUGR are at especially high risk. Pre-term neonates, at gestational ages of 33-36 weeks demonstrate less damage in the integrity of the lipid molecules, a significant accumulation of the harmful oxidant $\mathrm{ONOO}^{-}$cannot be detected, and the expressions of genes coding for antioxidant markers are less affected. The significantly lower LPO in the premature neonates may be correlated with the decreased sensitivity of the RBCs to oxygen radicals, or with the fact that the RBCs of premature newborns contain a smaller quantity of unsaturated fatty acids [36]. This phenotype is not without precedent. The GSH and NADPH levels proved to be lower in those with gestational ages of less than 33 weeks than in pre-term infants with gestational ages of 33-36 weeks, and the levels of these markers were as low in fullterm, small-for-age infants as in pre-term infants with gestational ages of less than 33 weeks [7].

\section{Conclusions}

Our data furnish evidence that there is extreme heterogeneity in ROS production and in the activation of the antioxidant defence system within neonates with IUGR, which is blunted by the use of mean measurements. Intergrouping based on gestational age and birthweight, yielded evidence that the molecular results in the pre-term IUGR group were often similar to those for the mature, appropriatefor-age neonates. However, the background of the IUGR phenotype is pleiotropic, and measurements of various antioxidants provide only a partially adequate picture of the overall condition of the neonates. Data emerging from different approaches to the topic present evidence only of the involvement of additional marker molecules in the development of IUGR disorders. Our study indicates that the levels of expression of the $m t$ and ho genes are good candidates through which to characterize the IUGR phenotype.

\section{Conflict of interest statement}

The authors declare that there are no conflicts of interest.

\section{References}

[1] Finer N, Leone T. Oxygen saturation monitoring for the preterm infant: the evidence basis for current practice. Pediatr Res 2009;65:375-80.

[2] Perrone S, Tataranno ML, Stazzoni G, Buonocore G. Biomarkers of oxidative stress in fetal and neonatal diseases. J Matern Fetal Neonatal Med 2012;25:2575-8.

[3] Thornton JG, Hornbuckle J, Vail A, Spiegelhalter DJ, Levene M. Infant wellbeing at 2 years of age in the Growth Restriction Intervention Trial (GRIT): multicentred randomised controlled trial. Lancet 2004;364:513-20.

[4] Bizon A, Milnerowicz-Nabzdyk E, Zalewska M, Zimmer M, Milnerowicz H. Changes in pro/antioxidant balance in smoking and non-smoking pregnant women with intrauterine growth restriction. Reprod Toxicol 2011;32:360-7.

[5] Kalanithi LE, Illuzzi JL, Nossov VB, Frisbaek Y, Abdel-Razeq S, Copel JA, Norwitz ER. Intrauterine growth restriction and placental location. J Ultrasound Med 2007;26:1481-9.
[6] Buonocore G, Perrone S. Biomarkers of oxidative stress in the fetus and newborn. Haemat Rep 2006;2:103-7.

[7] Lee YS, Chou YH. Antioxidant profiles in full term and preterm neonates. Chang Gung Med J 2005;28:846-51.

[8] McFarland VA, Inouye LS, Lutz CH, Jarvis AS, Clarke JU, McCant DD. Biomarkers of oxidative stress and genotoxicity in livers of field-collected brown bullhead, Ameiurus nebulosus. Arch Environ Contam Toxicol 1999;37:236-41.

[9] George SC, Hogman M, Permutt S, Silkoff PE. Modeling pulmonary nitric oxide exchange. J Appl Physiol 2004;96:831-9.

[10] Thibeault DW. The precarious antioxidant defenses of the preterm infant. Am J Perinatol 2000;4:167-81.

[11] Aschner M, Syversen T, Souza DO. Metallothioneins: mercury species-specific induction and their potential role in attenuating neurotoxicity. Exp Biol Med 2006;231:1468-73.

[12] Sedlak TW, Snyder SH. Bilirubin benefits: cellular protection by a biliverdin reductase antioxidant cycle. Pediatrics 2004;113:1776-82.

[13] Otterbein LE, Choi AM. Heme oxygenase: colors of defense against cellular stress. Am J Physiol Lung Cell Mol Physiol 2000;279:1029-37.

[14] Myatt L, Brewer A, Brockman DE. The action of nitric oxide in the perfused human fetal-placental circulation. Am J Obstet Gynecol 1991;164: 687-92.

[15] Fox SB, Khong TY. Lack of innervation of human umbilical cord. An immunohistological and histochemical study. Placenta 1990;11:59-62.

[16] Krause BJ, Prieto CP, Muñoz-Urrutia E, San Martín S, Sobrevia L, Casanello P. Role of arginase-2 and eNOS in the differential vascular reactivity and hypoxia-induced endothelial response in umbilical arteries and veins. Placenta 2012;33:360-6.

[17] Radi R, Peluffo G, Alvarez MN, Naviliat M, Cayota A. Unraveling peroxynitrite formation in biological systems. Free Radic Biol Med 2001;30:463-88.

[18] Nuwaysir EF, Bittner M, Trent J, Barrett JC, Afshari CA. Microarrays and toxicology. The advent of toxicogenomics. Mol Carcinogen 1999;24:153-9.

[19] Lowry OH, Rosebrough EA, Farr AL, Randall RJ. Protein measurement with Folin phenol reagent. J Biol Chem 1951;193:265-75.

[20] Misra HP, Fridovich I. The role of superoxide anion in the autoxidation of epinephrine and a simple assay for superoxide dismutase. J Biol Chem $1972 ; 247: 3170-5$

[21] Beers Jr RF, Sizer IW. Catalase assay with special reference to manometric methods. Science 1953;117:710-2.

[22] Nogueira CW, Quinhones EB, Jung EAC, Zeni G, Rocha JBT. Anti-inflammatory and antinociceptive activity of biphenyl diselenide. Inflamm Res 2003;52: 56-63.

[23] Serbinova E, Khwaja S, Reznick AZ, Packer L. Thioctic acid protects against ischemia-reperfusion injury in the isolated perfused Langendorff heart. Free Radic Res 1992;17:49-58.

[24] Villegas E, Gilliland SE. Hydrogen peroxide production by Lactobacillus delbrueckii Subsp Lactis I at $5^{\circ} \mathrm{C}$. J Food Sci 1998;63:1070-4

[25] Huie RE, Padmaja S. The reaction of NO with superoxide. Free Radic Res Com 1993;18:195-9.

[26] Nanetti L, Giannubilo SR, Raffaelli F, Curzi CM, Vignini A, Moroni C, et al. Nitric oxide and peroxynitrite platelet levels in women with small-for-gestationalage fetuses. BJOG 2008;115:14-21.

[27] Johnson RA, Kozma F, Colombari E. Carbon monoxide: from toxin to endogenous modulator of cardiovascular functions. Braz J Med Biol Res 1999;32:1-14

[28] Moncada S, Palmer RM, Higgs EA. Nitric oxide: physiology, pathophysiology, and pharmacology. Pharmacol Rev 1991;43:109-42.

[29] Vreman HJ, Wong RJ, Kim EC, Nabseth DC, Marks GS, Stevenson DK. Haem oxygenase activity in human umbilical cord and rat vascular tissues. Placenta 2000;21:337-44.

[30] Zhao H, Wong RJ, Kalish FS, Nayak NR, Stevenson DK. Effect of heme oxygenase1 deficiency on placental development. Placenta 2009;30:861-8.

[31] Zapata CL, Simões TM, Donangelo CM. Erythrocyte metallothionein in relation to other biochemical zinc indices in pregnant and nonpregnant women. Biol Trace Elem Res 1997;57:115-24.

[32] Kägi JH, Schäffer A. Biochemistry of metallothionein. Biochemistry 1988;27; 8509-15.

[33] Goyer RA, Haust MD, Cherian MG. Cellular localization of metallothionein in human term placenta. Placenta 1992;13:349-55.

[34] Davis SR, Cousins RJ. Metallothionein expression in animals: a physiological perspective on function. J Nutr 2000;130:1085-8.

[35] McAleer MF, Tuan RS. Cytotoxicant-induced trophoblast dysfunction and abnormal pregnancy outcomes: role of zinc and metallothionein. Birth Defects Res C Embryo Today 2004;72:361-70.

[36] Varga SI, Novák Z, Pataki L, Patocskai M, Matkovics B. The influence of antioxidants on the oxidative stress of red blood cells. Clin Chim Acta 1992;205:241-4. 